\title{
Cell response and corrosion behavior of electrodeposited diamond-like carbon films on nanostructured titanium
}

\author{
T.M. Manhabosco ${ }^{\mathrm{a}, *}$, L.A.M. Martins ${ }^{\mathrm{c}}$, S.M. Tamborim ${ }^{\mathrm{b}}$, M. Ilha ${ }^{\mathrm{c}}$, M.Q. Vieira ${ }^{\mathrm{c}}$, F.C.R. Guma ${ }^{\mathrm{c}}$, I.L. Müller ${ }^{\mathrm{d}}$ \\ ${ }^{a}$ Physics Department, Federal University of Ouro Preto, Campus Universitário Morro do Cruzeiro/ICEB/DEFIS/35400-000, Ouro Preto, Minas Gerais, Brazil \\ ${ }^{\mathrm{b}}$ Technology Center of Alegrete, Federal University of Pampa, Av. Tiarajú/ 810, 97546-550, Alegrete, Rio Grande do Sul, Brazil \\ ${ }^{\mathrm{c}}$ Department of Biochemistry, Federal University of Rio Grande do Sul, Av. Ramiro Barcelos 2600, 90035-003 Porto Alegre, Rio Grande do Sul, Brazil \\ ${ }^{\mathrm{d}}$ Metallurgy Department, Laboratory of Corrosion Research, Federal University of Rio Grande do Sul, Av. Bento Gonçalves 9500/75/232, 91501-970 Porto Alegre, Rio Grande do \\ Sul, Brazil
}

\section{A R T I C L E I N F O}

\section{Article history:}

Received 2 May 2012

Accepted 11 September 2012

Available online 26 September 2012

\section{Keywords:}

A. Titanium

B. AFM

B. EIS

B. SEM

C. Electrodeposited films

\begin{abstract}
A B S T R A C T
Surface characteristics such as roughness and contact angle of flat and nanostructured titanium samples and diamond-like carbon films (DLC) electrodeposited on the nanostructured samples were evaluated. Also, the mechanical properties and the corrosion resistance of the samples were evaluated in phosphate buffered saline (PBS). Biocompatibility was assessed by analyzing an in vitro cell culture. Nanostructured samples presented better cell biocompatibility. DLC deposited onto nanostructured samples remained with nanostructured morphology, presented high hardness and improved corrosion resistance compared to bare titanium. The DLC films electrodeposited from acetonitrile presented higher corrosion resistance in PBS solution when compared to DLC films deposited from $\mathrm{N}, \mathrm{N}$-dimethylformamide.
\end{abstract}

(c) 2012 Elsevier Ltd. All rights reserved.

\section{Introduction}

Metals and alloys used as implant materials must be biocompatible, non-toxic, and resistant to corrosion and other properties, such as stress, wear and fatigue depending on the application. Despite the large variety of metals and alloys it is mandatory for a biomaterial to be corrosion resistant, as the body fluid is a hostile environment. Likewise, corrosion products are generally metal salts that can be harmful to the cells causing inflammation and necrosis. Among the metals, titanium (Ti) and its alloys have better corrosion resistance and also good biocompatibility due to the presence of a thin and compact titanium oxide film present on their surface [1-3].

Many studies have been carried out in order to improve the surface characteristics and properties of the titanium and its alloys, since the initial response of the surrounding living cells to an implant is closely related to these parameters, for instance, surface roughness, wettability, chemical composition, morphology, etc [2-5]. Elias et al. [2] performed different surface treatments on $\mathrm{Ti}$ dental implants and studied the effect of the surface roughness, contact angle, and surface morphology on the implant removal torque. The implants were subjected to sandblasting treatments, acid

\footnotetext{
* Corresponding author. Address: Campus Universitário Morro do Cruzeiro/ICEB/ DEFIS, Ouro Preto, Minas Gerais 35400-000, Brazil. Tel.: +55 31 35591675; fax: +55 3135591667.

E-mail address: taisemanhabosco@gmail.com (T.M. Manhabosco).
}

etching and anodizing. It was observed that the increase in roughness up to a certain value increases the removal torque; when the value is higher than a critical value the removal torque is reduced. Authors also observed that wettability influenced the adsorption and adhesion of implants since the anodized implants present a lower contact angle and higher removal torque. Das et al. [3] studied the biocompatibility of titania nanotubes grown via anodization on titanium sheets in different electrolyte compositions. Authors verified that a nonporous oxide surface leads to a poor cellular attachment at the same time as better cellular attachment and spreading is noticed on the nanoporous oxide surface. The nanoporous oxide surface also presented lower contact angle and higher surface energy conditions ascribed to materials with good biocompatibility.

One of main applications of titanium as a biometal is in dentistry, especially in dental implants, due to good biocompatibility and good corrosion resistance [1-3,6]. However, in an oral environment the mechanical properties of titanium may not be appropriate, as titanium possesses a high friction coefficient and low wear resistance $[7,8]$. Biocompatible candidates capable of meeting these requirements are the diamond-like carbon films (DLC), which present high hardness, low friction coefficient, high wear resistance besides bio and hemocompatibilities [6,9-15]. Kim et al. [6] studied the extent of abutment screw loosening of $1 \mu \mathrm{m}$ thick DLC-coated and non-coated titanium dental implants. The authors observed that DLC-coated dental implants were more resistant to 
screw loosening. A US patent taken out by Kumar and Kennard [16] presents diamond-like carbon coated dental retaining screws as promising dental screws. The screws coatings are composed by diamond-like carbon, amorphous diamond, crystalline diamond or a combination of them. The coating confers a low friction surface finish, permitting improved preloading of the screw, and hence a high clamping force between the components of the dental prosthetic implant stack.

Diamond-like carbon (DLC) films are a new class of materials and a variety of coatings are named DLC. Basically, DLC is an amorphous carbon with a significant fraction of $\mathrm{CC} \mathrm{sp} 3$ bonds that may contain hydrogen in different amounts [17]. The DLC composition and its properties are closely related to deposition technique, parameters of deposition and incorporation of elements in the film network [13,14]. Meunier et al. [10] studied the biocompatibility, structure and hardness of hydrogenated and unhydrogenated carbon films deposited by cathodic vacuum arc (FCVA) technique onto Ti-6Al-4V substrate. The authors observed a decrease in the hardness and an increase in the $\mathrm{C}-\mathrm{C} \mathrm{sp}{ }^{2}$ bonds content when the hydrogen increased from 1 to 8 at.\% in the film. Cultured cells presented a spread out aspect, multiple microvilli and spheric structure but no difference in adhesion kinetic could be observed for carbon coatings and Ti-6Al-4V samples. Cheng et al. [13] investigated the microstructure, composition, wettability and biocompatibility of DLC films doped with different titanium concentrations obtained via co-sputtering. The study indicated that as the titanium content increased the amount of $\mathrm{sp}^{2}$ content and hydrophilicity also increased. The capability of cell differentiation and proliferation was also increased indicating superior biocompatibility when $\mathrm{Ti}$ is added to the diamond-like carbon film network.

Despite many studies on DLC film properties, the biocompatibility or cellular response to the electrodeposited DLC has not yet been investigated. The biocompatibility, corrosion and mechanical study of the electrodeposited DLC films is of interest as the electrodeposition technique is inexpensive and can be performed at room conditions, i.e., no vacuum or high temperature are needed. In the present work extensive research is presented about the influence of the nanostructure on titanium and DLC films on the survival and proliferation of femur osteoblast (F-OST) cells. The films were obtained by the electrodeposition technique onto titanium substrates from organic liquids. Other important properties of biomaterials such as corrosion and mechanical behavior were also evaluated.

\section{Experimental details}

\subsection{Sample pretreatment}

Ti samples (Grade 1, see composition in Table 1), $9.51 \mathrm{~mm}$ in diameter and $0.63 \mathrm{~mm}$ thick were mechanically cut from a titanium plate. A group of samples was wet-ground with SiC emery paper to 800 grit and polished with colloidal silica. After polishing the samples were ultrasonically cleaned in acetone for $10 \mathrm{~min}$ followed by rinsing in methanol and bi-distilled water. Another group was wet-ground with successively finer grit SiC until 4000 and

Table 1

Chemical composition of titanium samples (Grade 1).

\begin{tabular}{ll}
\hline Element & Composition (wt.\%) \\
\hline $\mathrm{N}$ & $\leqslant 0.009$ \\
$\mathrm{C}$ & $\leqslant 0.004$ \\
$\mathrm{H}$ & $\leqslant 0.002$ \\
$\mathrm{Fe}$ & $\leqslant 0.03$ \\
$\mathrm{O}$ & $\leqslant 0.0085$ \\
$\mathrm{Ti}$ & Balance \\
\hline
\end{tabular}

electrochemically polished in a solution $60 \%(\mathrm{v} / \mathrm{v}) \mathrm{H}_{2} \mathrm{SO}_{4}, 30 \%(\mathrm{v} /$ v) $\mathrm{HF}$ and $10 \%(\mathrm{v} / \mathrm{v})$ glycerin at a current density of $0.29 \mathrm{~A} / \mathrm{cm}^{2}$ for $2 \mathrm{~min}$. The temperature solution was controlled at $0-3^{\circ} \mathrm{C}$. After electropolishing, samples were rinsed with bi-distilled water, immersed in ethanol and sonicated for $10 \mathrm{~min}$. After that, samples were placed for $1 \mathrm{~h}$ in ethanol to avoid staining the surface. Finally, the samples were cleaned with bi-distilled water.

\subsection{Film deposition}

Diamond-like carbon films were obtained by electrodeposition from analytical pure organic liquids, acetonitrile (DLC/ACT) and $\mathrm{N}, \mathrm{N}$-dimethylformamide (DLC/DMF), by applying $1200 \mathrm{~V}$ between the $4 \mathrm{~mm}$ distant electrodes. The depositions were carried out for $24 \mathrm{~h}$ at $25^{\circ} \mathrm{C}$.

Films thicknesses up to $1 \mu \mathrm{m}$ were determined by perfilometry. DLC films deposited from acetonitrile were less thick, which can be inferred from the chronoamperometric curves and deposition process presented elsewhere [15].

\subsection{Film and surface characterization}

The electrodeposited films were characterized by Raman spectroscopy with an NTEGRA Spectra Nanofinder (NT-MDT) operating with a blue laser ( $488 \mathrm{~nm}$ ) at room temperature.

The morphological characterization of titanium surfaces and DLC films before and after EIS (Electrochemical Impedance Spectroscopy) measurements was carried out by an atomic force microscope (AFM - Shimadzu, model SPM-9500J3). The sample surface roughness was evaluated for a scan area of $2.5 \times 2.5 \mu \mathrm{m}$ using the microscope software.

Wettability, an inverse measure of contact angle, was evaluated by contact angle measurements. Prior to the contact angle measurements, samples were cleaned ultrasonically in acetone, ethanol and bi-distilled water for $10 \mathrm{~min}$. The contact angles were determined using the sessile drop method at room temperature. The water drop image was stored by a video camera and an image analysis system calculated the contact angle $(\theta)$ from the shape of the drop.

\subsection{Mechanical behavior}

The hardness of the DLC coatings was acquired from manoindentation tests using a Fischerscope HV100 nanohardness tester. The maximum load in each indentation was $100 \mathrm{mN}$ to avoid penetration depth greater than $20 \%$ of the film thickness. A Vickers indenter and the Oliver and Pharr [18] method were used to determine hardness.

\subsection{Corrosion behavior}

EIS measurements were carried out to evaluate the corrosion behavior of the two different finished titanium surfaces and diamond-like carbon films deposited on electropolished titanium samples. Impedance data for $1 \mathrm{~h}, 7$ and 16 day periods of immersion were acquired by a potentiostat (AUTOLAB PGSTAT 30) and a frequency response analyzer (FRA) system operating at open circuit potential (OCP) in a frequency range from $100 \mathrm{kHz}$ to $3 \mathrm{mHz}$ with a perturbation of $\pm 10 \mathrm{mV}$. The EIS measurements were carried out in a three-electrode cell containing phosphate buffer saline (PBS) solution at $37^{\circ} \mathrm{C}\left( \pm 1^{\circ} \mathrm{C}\right)$ in order to simulate the body environment. The solution ( $\mathrm{pH}$ 7.1) was composed by $8 \mathrm{~g} \mathrm{~L}^{-1} \mathrm{NaCl}$; $0.2 \mathrm{~g} \mathrm{~L}^{-1} \mathrm{KCl} ; 0.594 \mathrm{~g} \mathrm{~L}^{-1} \mathrm{Na}_{2} \mathrm{HPO}_{4}$ and $0.2 \mathrm{~g} \mathrm{~L}^{-1} \mathrm{KH}_{2} \mathrm{PO}_{4}$. A saturated calomel reference electrode was used as reference electrode and a platinum $(\mathrm{Pt})$ wire as counter electrode. 


\subsection{Cell culture}

To evaluate cellular response to the samples, $4 \times 10^{4}$ of murine femur osteoblastic cells (F-OST), obtained from the Rio de Janeiro Cell Bank (HUCFF, UFRJ, RJ), were seeded under titanium pieces placed on 12 well culture plates (Nunc, Roskilde, Denmark) for $24 \mathrm{~h}$. The cells were maintained in Dulbecco's Modified Eagle's Medium (DMEM, Invitrogen, Carlsbad, CA, USA) supplemented with $15 \%$ fetal bovine serum (FBS, Cultilab, Campinas, Brazil) and $2 \mathrm{~g} / \mathrm{L}$ HEPES buffer ( $\mathrm{pH} 7.4$ ) in a humidified atmosphere with $5 \%$ $\mathrm{CO}_{2}$ at $37^{\circ} \mathrm{C}$.

\subsection{Cellular morphology images}

After $24 \mathrm{~h}$ of culture, the attached cells were washed with $0.1 \mathrm{M}$ phosphate buffer ( $\mathrm{pH} 7.3$ ) and fixed with $2.5 \%$ glutaraldehyde for 7 days. The cells were post fixed in osmium tetroxide $\left(\mathrm{OsO}_{4}\right) 1 \%$ in phosphate buffer for 30 min rinsed in the same buffer and dehydrated in acetone in ascending concentrations (30-100\%). The samples were coated with gold in sputter coater and viewed at $15 \mathrm{Kv}$ accelerating voltage under a scanning electron microscope (SEM, Jeol JSM 6060).

\subsection{Colorimetric MTT assay}

This test evaluates cell viability and proliferation by quantifying the cellular dehydrogenase activities that reduce MTT (3-4,5-dimethylthiazolyl-2,5-diphenyl-2H-tetrazolium bromide) to a purple formazan salt [19]. After $48 \mathrm{~h}$ of culture, the cells were incubated with $1 \mathrm{mg} / \mathrm{mL}$ MTT for $2 \mathrm{~h}$ at $37^{\circ} \mathrm{C}$ in the dark. The cells were then lysed in dimethylsulfoxide (DMSO, Sigma Inc., Saint Louis, MO, USA), the purple formazan crystals were dissolved, and the lysates were measured in a microplate spectrophotometer (Spectra Max 190, Molecular Devices, USA) at $570 \mathrm{~nm}$ and $630 \mathrm{~nm}$. To quantify cellular content for MTT results normalization, proteins were measured by Lowry's modified assay [20]. Results were expressed as MTT absorbance per $\mu \mathrm{g}$ of protein.

\subsection{Statistical analysis}

MTT statistical analysis was performed using the SPSS software (IBM Corporation, New York, US). These results were representative of two independent experiments, each one with $n=4$. The data were expressed as the means $\pm \mathrm{SE}$ of the mean. One-way ANOVA was used to analyze the cellular response to the titanium samples during the established culture time. A post-hoc Duncan multiple range test was performed. The results were considered statistically significant when the $p$ values were equal to or less than 0.05 .

\section{Results and discussion}

\subsection{Surface characterization}

\subsubsection{Raman spectroscopy}

Fig. 1 presents the typical Raman spectra for films deposited during $24 \mathrm{~h}$ from acetonitrile and DMF. Deconvolution of the spectra with Gaussian shape reveals two peaks around $1360 \mathrm{~cm}^{-1}$ (D peak) and $1580 \mathrm{~cm}^{-1}$ (G peak) as previously published [15]. In the spectra, the slope of the photoluminescence background is observed which is due to the hydrogen content in the film. According to Eq. (1) presented by Casiraghi [17], which allows a qualitative hydrogen estimation of hydrogenated amorphous carbons materials, a 39\% hydrogen content was estimated in the electrodeposited films obtained from acetonitrile and $43 \%$ for that obtained from DMF. Regarding the hydrogen amount and further presented

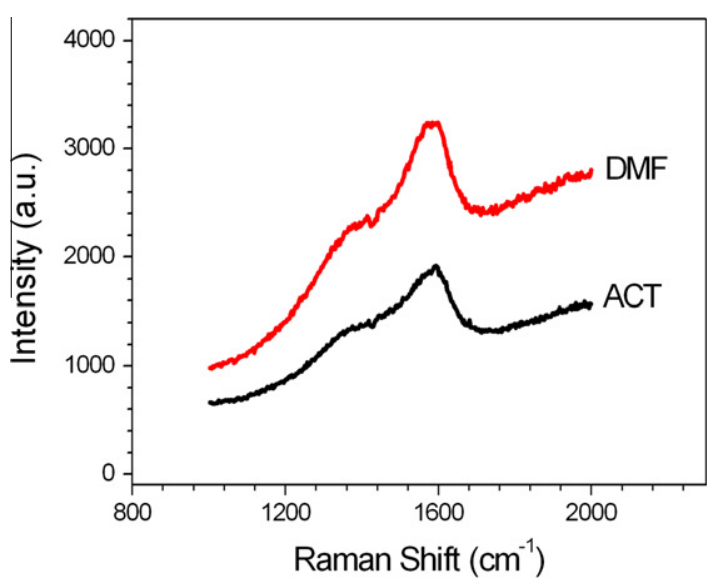

Fig. 1. Raman spectrum of electrodeposited film from acetonitrile and DMF.

nanohardness measurements, we classify the films as a-C:H (hydrogenated amorphous carbon) with intermediate $\mathrm{H}$ content (20-40\%), also called diamond-like carbon films.

\subsubsection{AFM analysis}

The sample roughness evaluated from images obtained with AFM is shown in Table 2. Mechanically finished samples present a flat surface with extremely low root mean surface roughness and a maximum roughness depth $\left(R_{\mathrm{y}}\right)$ of $19.9 \mathrm{~nm}$. The group of electrochemically polished samples presented a root mean surface roughness 10 times greater than the mechanically finished ones. AFM images (Fig. 2) reveal the formation of nanostructures on the surface, $120.8( \pm 15.1) \mathrm{nm}$ in diameter and $22.9( \pm 3.4) \mathrm{nm}$ in height. DLC films deposited on nanostructured surfaces copied the morphologic structure of the surface and maintain the nanostructure while the roughness increases as film grows. Table 2 also shows that DLC films deposited from DMF presented greater roughness compared to that obtained from acetonitrile, which may be due to greater thickness confirmed by perfilometry and reported in a previous work [15].

\subsubsection{Contact angle measurements}

The measured contact angle of all surfaces analyzed is less than $90^{\circ}$ indicating hydrophilic surfaces, which are favorable to adhesion, spread and proliferation of cells [21]. The polished process, i.e., mechanical or electrochemical, slightly changes the contact angle of the samples probably because the surface becomes rougher (10 times higher) and the surface oxide probably does not have any outermost chemical groups.

DLC films also present contact angles in the same order of magnitude as titanium samples indicating good wettability what is one of required parameters for cell adsorption and adhesion. The hydrophobic or hydrophilic character of DLC films depends on the film composition and dopant, deposition technique, parameters and deposition conditions [13,14]. Cheng et al. [13] deposited DLC films with titanium dopant by co-sputtering and observed that higher the titanium contents the better the wettability. Grischke et al. [14] deposited hard DLC coatings with low surface energy by incorporation of silicon into the matrix of the DLC network. They also modified the DLC and silicon-containing DLC network with oxygen and enabled an independent variation of the polar and dispersive component of the surface energy over a broad range.

The contact angle difference observed for DLC films deposited from acetonitrile and DMF could be related to $\mathrm{sp}^{3} / \mathrm{sp}^{2}$ ratio and/ or $\mathrm{H}$ percentage in the films, as already observed by other authors 
Table 2

Contact angle measurements for titanium samples after different treatments.

\begin{tabular}{|c|c|c|c|}
\hline Sample & Roughness $\left(R_{\mathrm{ms}}\right)(\mathrm{nm})$ & Roughness $\left(R_{y}\right)(\mathrm{nm})$ & Contact angle \\
\hline Flat $\mathrm{Ti}$ & $1.5( \pm 0.1)$ & $19.9( \pm 1.7)$ & $87.0^{\circ}( \pm 2.3)$ \\
\hline Nanostructured Ti & $15.9( \pm 1.0)$ & $73.7( \pm 7.7)$ & $81.8^{\circ}( \pm 0.8)$ \\
\hline DLC/DMF on nanostructured $\mathrm{Ti}$ & $21.3( \pm 1.7)$ & $147.3( \pm 19.8)$ & $85.3^{\circ}( \pm 1.9)$ \\
\hline DLC/ACT on nanostructured $\mathrm{Ti}$ & $19.8( \pm 2.1)$ & $135.3( \pm 16.6)$ & $82.2^{\circ}( \pm 3.5)$ \\
\hline
\end{tabular}

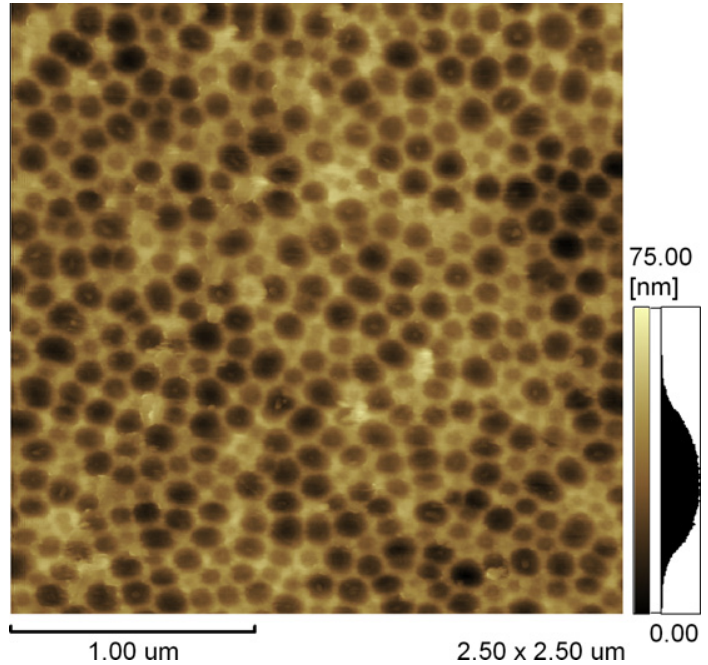

Fig. 2. AFM image for electropolished titanium sample.

$[22,23]$. It can be seen that films deposited from DMF present a higher contact angle and $\mathrm{H}$ content than that obtained from acetonitrile. Ostrovskaya [23] found that the hydrogenation of the polycrystalline diamond film surface increases the contact angle $\left(\theta=93^{\circ}\right)$ if compared to the contact angle on the surface oxidized by air $\left(\theta=32^{\circ}\right)$. However, as the $\mathrm{sp}^{3} / \mathrm{sp}^{2}$ ratio was not determined in the present work, the dependence on $\mathrm{sp}^{3} / \mathrm{sp}^{2}$ ratio or on hydrogen content cannot be assumed.

\subsection{Mechanical behavior}

In a previous study [15], DLC films were deposited from acetonitrile and DMF during $4 \mathrm{~h}$ with the same parameters used in this work. The wear resistance of the films was tested at dry conditions with a ball-on-plate tribometer by applying a normal force of $2 \mathrm{~N}$ and sliding velocity of $2 \mathrm{~mm} / \mathrm{s}$. Low friction coefficient, about 0.1 , was observed for the electrodeposited films obtained from DMF. Films deposited from acetonitrile presented a fast removal due to the extremely low thickness (less than $40 \mathrm{~nm}$ ). The lower thickness of the films obtained from acetonitrile is related to the lower current transport during the electrodeposition process.

DLC films obtained in the present work, i.e., deposited from acetonitrile and DMF during $24 \mathrm{~h}$, showed a nanohardness between 9.5 and $15.9 \mathrm{GPa}$ while the titanium substrate nanohardness was evaluated as being 1.6 GPa. The dispersion in the DLC film nanohardness occurred because, in case of films obtained from acetonitrile, the film thickness was less than $1 \mu \mathrm{m}$ and the penetration depth was higher than $20 \%$. In these cases, the nanohardness value represents a combined value of the substrate and film hardness. In the literature it is possible to find a wide range of hardness values for DLC films depending on the presence of hydrogen in the film network and its content, the doping elements ( $\mathrm{Si}, \mathrm{Ti}, \mathrm{W}$ and others), the technique used and so on [12,17,21,24]. Hu et al. [25] obtained electrodeposited DLC films on silicon substrates from DMF organic liquid at $1400 \mathrm{~V}$ with and without the presence of carbon nanotubes (CNTs). The 10.28 GPa nanohardness of the DLC films was increased to $12.47 \mathrm{GPa}$ when nanotubes were incorporated to the films. Yan et al. [26] prepared hydrogenated amorphous carbon films on silicon substrates using the electrolysis of ethanol at different voltages and observed that hardness and Young's modulus increased with the voltage. The reported nanohardness values were from $7.71 \mathrm{GPa}$ up to $15.04 \mathrm{GPa}$.

\subsection{Corrosion behavior}

The EIS data for bare nanostructured titanium immersed in PBS solution are shown as Bode plots in Figs. 3-5 for immersion times of 1 h, 7 and 16 days. Fig. 3 shows a capacitive behavior in a wide frequency range with phase angle values of about $-86^{\circ}$ for $1 \mathrm{~h}$ of immersion. The EIS spectrum of uncovered titanium changes completely from $1 \mathrm{~h}$ to 7 days of immersion, showing instead of one

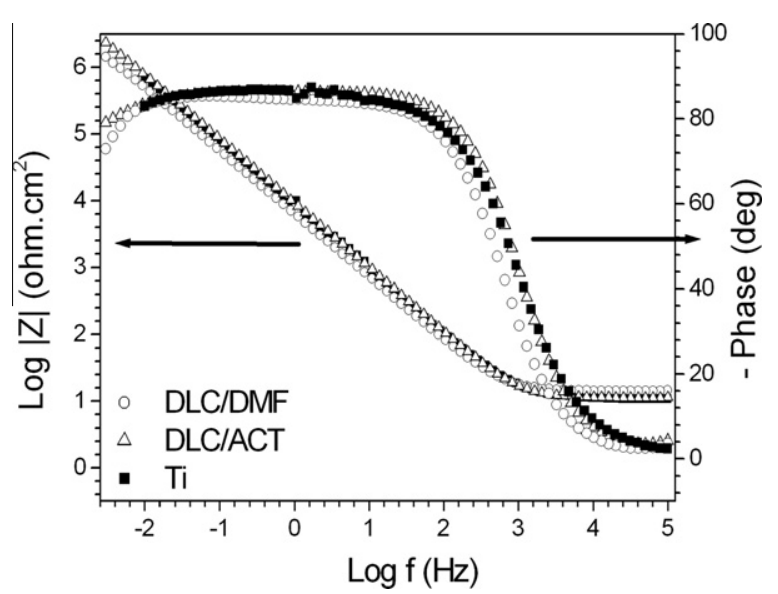

Fig. 3. Bode Diagrams of nanostructured titanium uncovered ( $\square$ ) and covered by $\operatorname{DLC} / \mathrm{DMF}(\mathrm{O})$ and DCL/ACT $(\Delta)$ immersed in PBS solution for a $1 \mathrm{~h}$ period.

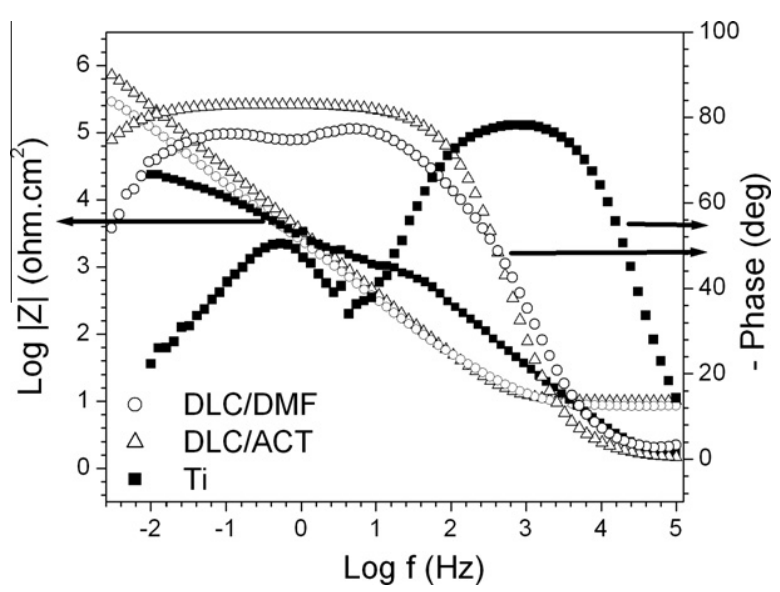

Fig. 4. Bode Diagrams of nanostructured titanium uncovered ( $\mathbf{\square})$ and covered by $\operatorname{DLC} / \mathrm{DMF}(O)$ and DLC/ACT $(\Delta)$ immersed in PBS solution for a 7 days period. 


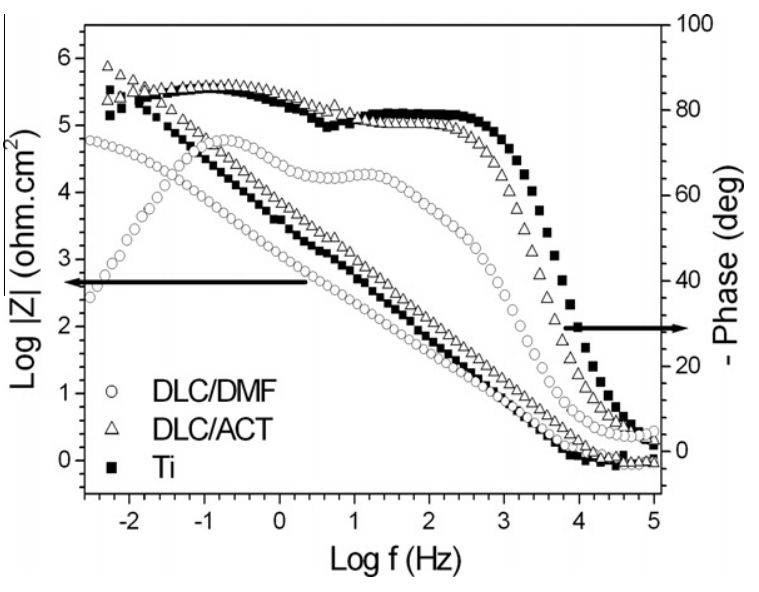

Fig. 5. Bode Diagrams of nanostructured titanium uncovered ( $\boldsymbol{\square})$ and covered by $\operatorname{DLC} / \operatorname{DMF}(O)$ and DLC/ACT $(\Delta)$ immersed in PBS solution for a 16 days period. time constant, two well defined ones. The time constant in the high frequency region, about $1000 \mathrm{~Hz}$ may be related to the metal/compact oxide interface and the second time constant, at about $1 \mathrm{~Hz}$ may be related to the interface Ti/PBS solution in pores as proposed in Fig. 6 (A). The proposal of a complex nanoporous surface containing open pores can be confirmed by the atomic force microscopy (AFM) characterization shown in Fig. 2. Even if the pores did not reach the metal, probably the film under them should be much thinner than in the rest of the layer and therefore would present different electrochemical characteristics. The time constant at $1 \mathrm{~Hz}$ indicates a diffusional behavior in accordance with the phase angle of $-50^{\circ}$. This diffusional phenomenon indicates that the surface treatment used allows the penetration of the nanopores by the PBS electrolyte.

The increase of the diffusional character after 7 days of immersion may be related to some salt precipitation, oxide growth or hydroxide formation that should be further investigated. The reduction of the diffusional behavior at 16 days of immersion can be associated with an increased resistance in the pores where
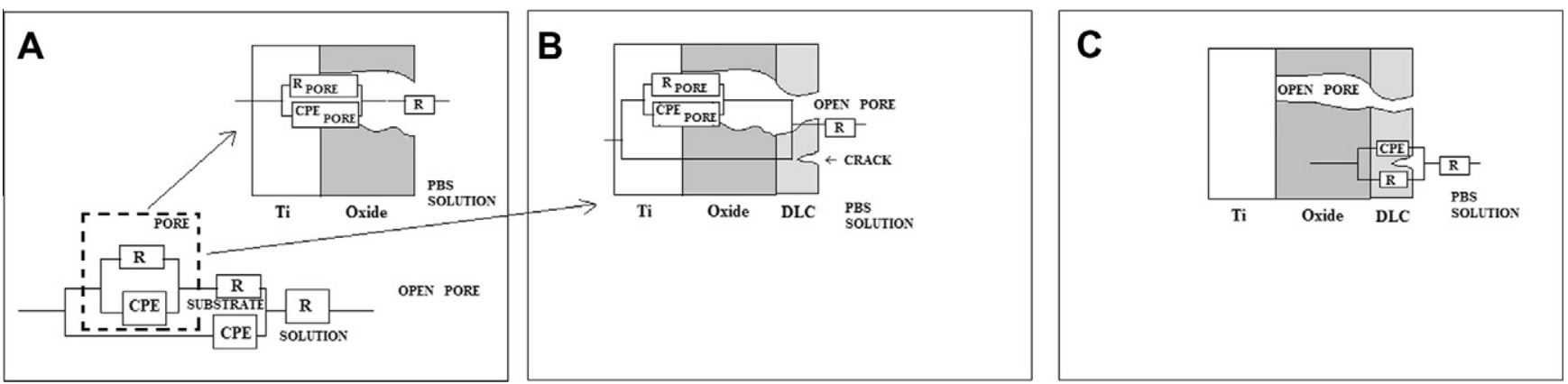

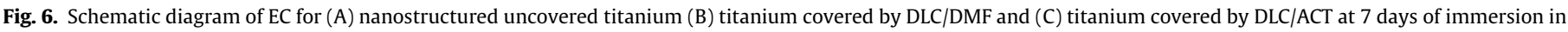
PBS solution.

Table 3

Simulated equivalent circuit for nanostructured titanium uncovered and covered by DLC/DMF or DLC/ACT after $1 \mathrm{~h}$ of immersion in PBS solution.

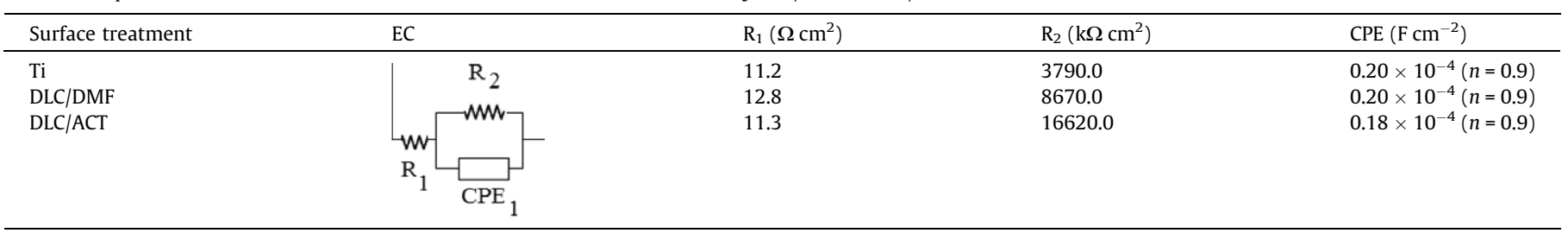

Table 4

Simulated equivalent circuit for nanostructured titanium uncovered and covered by DLC/DMF or DLC/ACT after 7 days of immersion in PBS solution.

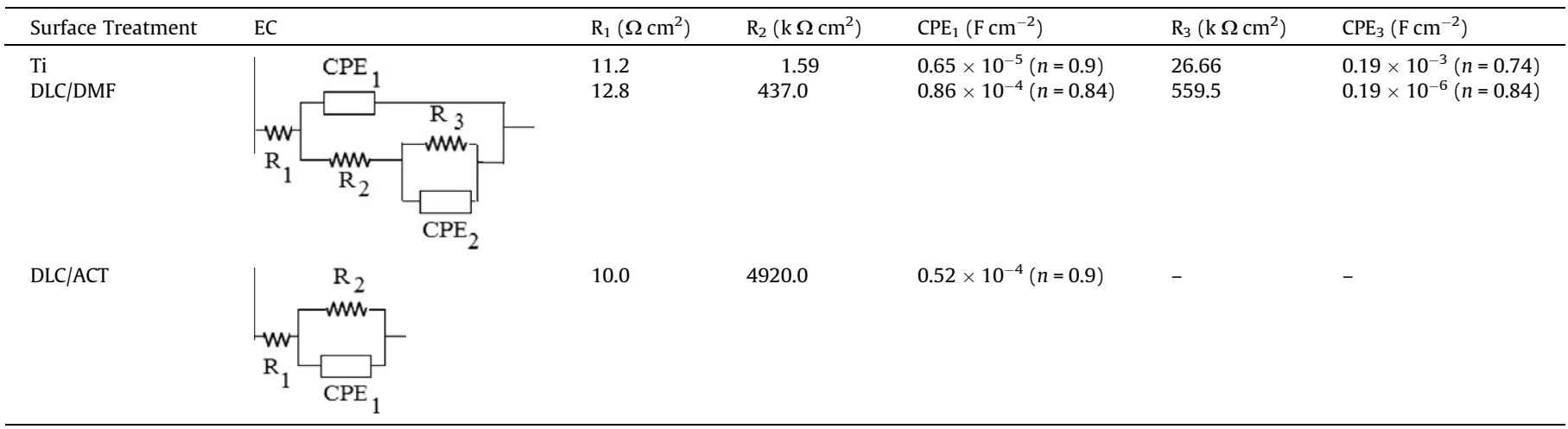


the electrolyte may now be blocked with precipitates, oxides or hydroxides.

The time constants separation from $1 \mathrm{~h}$ to 7 days is less sharp for DLC-coated titanium (Figs. 3 and 4). Nevertheless two overlapped time constants in a wide frequency range with an angle of about $-80^{\circ}$ are observed in the results of EIS for nanostructured titanium coated by DLC/DMF. These results of EIS for $1 \mathrm{~h}$ and 7 days can be represented by an equivalent circuit (EC) shown in Table 3 and 4, respectively. An EC containing only one time constant can be used to reproduce the results obtained in $1 \mathrm{~h}$ of immersion in PBS. However, after 7 days an EC containing at least two time constants must be used to model the electrochemical behavior of nanostructured titanium both uncovered and coated by DLC/DMF. Otherwise, for Ti covered with DLC/ACT an EC containing only one time constant was used even if the Bode diagram also suggested the presence of two time constants, because the software did not allow separating them. The EC used for only one time constant was $R_{S}\left(R_{2} \mathrm{CPE}_{1}\right)$ and the one with two time constants was $R_{s}\left(\mathrm{CPE}_{1}[-\right.$ $R_{2}\left(\mathrm{CPE}_{2} R_{3}\right)$ ]), where $R_{s}$ represents the solution resistance, $R_{2}$ the high frequencies resistance, $R_{3}$ stands for the lower frequencies resistance, and $\mathrm{CPE}_{1}$ and $\mathrm{CPE}_{2}$ represent constant phase elements which are obligatory when phase angles lower than $90^{\circ}$ are present. According to Table 3, higher values for $R_{2}$ are observed for Ti covered with DLC/ACT than respectively Ti covered with DLC/ DMF and uncovered Ti. This indicates the enhanced barrier effect provided by that first coating. The better corrosion performance of films obtained from acetonitrile compared to that obtained from DMF may be due to a lower incidence of nanocracks and/or uncovered areas (confirmed in a previous work [15]). The value of capacitances for $1 \mathrm{~h}$ and 7 days for DLC/ACT and the format of the diagrams are compatible with a nanostructured layer. The diffusional behavior for DLC/DMF covered Ti increased from 7 days to 16 days (Figs. 4 and 5). The lower phase angles are compatible with the model proposed by Lillard et al. [27], who reported some rough pits on the surface of a DLC layer on $\mathrm{Ni}$ which grew some 60$100 \mu \mathrm{m}$ into the bulk apparently due to an increase in tensions introduced into the film due to corrosion of the substrate metal. Titanium does not easily suffer pitting but is prone to crevice corrosion as has been shown by Galio et al. [28] for sintered specimens. As the DLC/DMF presents nanocracks this corrosion mechanism is a possibility; however it should be further investigated.

The evolution of impedance plots for Ti covered with DLC/ACT shows higher resistance values in the high frequency region than the specimens covered with DLC/DMF for all immersion times

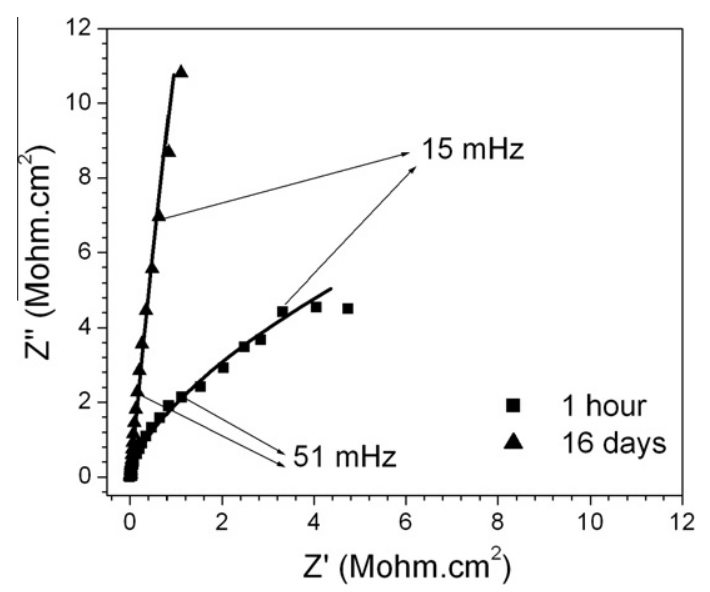

Fig. 7. Nyquist plots and fitting simulation of bare mechanically polished titanium immersed in PBS solution for a ( $\mathbf{\square}) 1 \mathrm{~h}$ and ( $\mathbf{\Delta}) 16$ days periods. tested, thus characterizing DLC/ACT as the best anti-corrosion film among the tested ones. The capacitive aspects of the EIS plots, which correspond to high charge storing, imply that DLC/ACT is the most homogeneous coating. The EIS results for 16 days were very difficult to model probably due to some precipitation, oxide growth or hydroxide formation which make the surface much more intricate, thus it was hard to compare these results with the ones of the other immersion times.

Nyquist diagrams (Fig. 7) present the simulated and experimental data for the mechanically polished Ti for $1 \mathrm{~h}$ and 16 days. Mechanically polished titanium shows a capacitive behavior for $1 \mathrm{~h}$ of immersion and a more visible diffusional behavior for 16 days of immersion. As foreseen, this kind of specimen shows the behavior of passive films, similar to what has been found by other authors [29]. Based on the resistance and capacitance values found, the simplest EC adequately representing the results of EIS for $1 \mathrm{~h}$ of immersion is $R_{S}\left(\mathrm{CPE}_{1} R_{1}\right)$ where: $R_{S}=8.0 \Omega \mathrm{cm}^{2} ; R_{1}$ $=631 \mathrm{k} \Omega \mathrm{cm}^{2} ; \mathrm{CPE}_{1}=13.0 \mu \mathrm{F} \mathrm{cm}^{-2}(n=0.9)$. The EC for 16 days of immersion is $R_{S}\left[C_{1}\left(R_{2} \mathrm{CPE}_{1}\right)\right]$, where: $R_{s}=2.4 \Omega \mathrm{cm}^{2} ; C_{1}$ $=9.3 \mu \mathrm{F} \mathrm{cm}^{-2} ; R_{2}=4.2 \mathrm{k} \Omega \mathrm{cm}^{2} ; \mathrm{CPE}_{1}=9.0 \mu \mathrm{F} \mathrm{cm}^{-2}(n=0.8)$.

Despite the corrosion studies indicate that DLC films increase the corrosion protection of titanium samples, it should be taken in mind that in a real situation, like in vivo, other processes besides corrosion act simultaneously. The processes, like wear-corrosion, crevice-corrosion and fatigue corrosion may increase the degradation of the coated samples in a complex way that can lead to a fast failure of the coating [30-32]. Also, it should be taken in account that the body fluid and the surrounding tissue of every implant is a harmful environment composed of cells, several kind of fluids and possibly bacteria. So, to adequately evaluate the corrosion resistance of the coated samples, some corrosion tests involving more complex fluids, wear-corrosion, corrosion fatigue processes should be performed.

\subsection{Biocompatibility}

To assess F-OST cellular morphology and attest cell adhesion on the different substrates, scanning electron microscope images were obtained and are shown in Fig. 8. The samples biocompatibility in this work was measured by evaluating the cells viability and proliferation through MTT method, which is shown in Fig. 9. Comparing F-OST cells seeded on flat titanium samples (Fig. 8 (A)) with cells seeded on nanostructured titanium samples (Fig. 8 (B)), it is clearly observed that cells present an excellent spread and covered almost the complete nanostructured surface. Long and fine cytoplasmatic extensions could also be observed in all directions, indicating good adhesion to the nanostructured substrate, what is in accordance with the lower contact angle and higher surface roughness presented by the nanostructured samples. These results were in accordance with Das et al. [3] that grew titania nanotubes on titanium by anodization and also observed higher cell adhesion and proliferation on nanotube surfaces than on surfaces with no nanotubes.

The DLC film electrodeposited from DMF or acetonitrile on nanostructured titanium (Fig. 8(C) and (D)) did not affect cell adhesion or morphology when compared to the nanostructured titanium without DLC film (Fig. 8(B)). This is an important aspect that indicates that the nanostructured DLC produced by the electrodeposition technique may be very biocompatible, since we observed no significative changes on the cell morphology in these groups. These findings were corroborated by the MTT assay, which was performed to access cell viability and proliferation by quantifying cellular dehydrogenase of adhered living cells. We observed that the F-OST cells presented higher viability and better proliferation under nanostructured titanium with or without DLC films than flat titanium (Fig. 9). Moreover, the MTT results showed that 

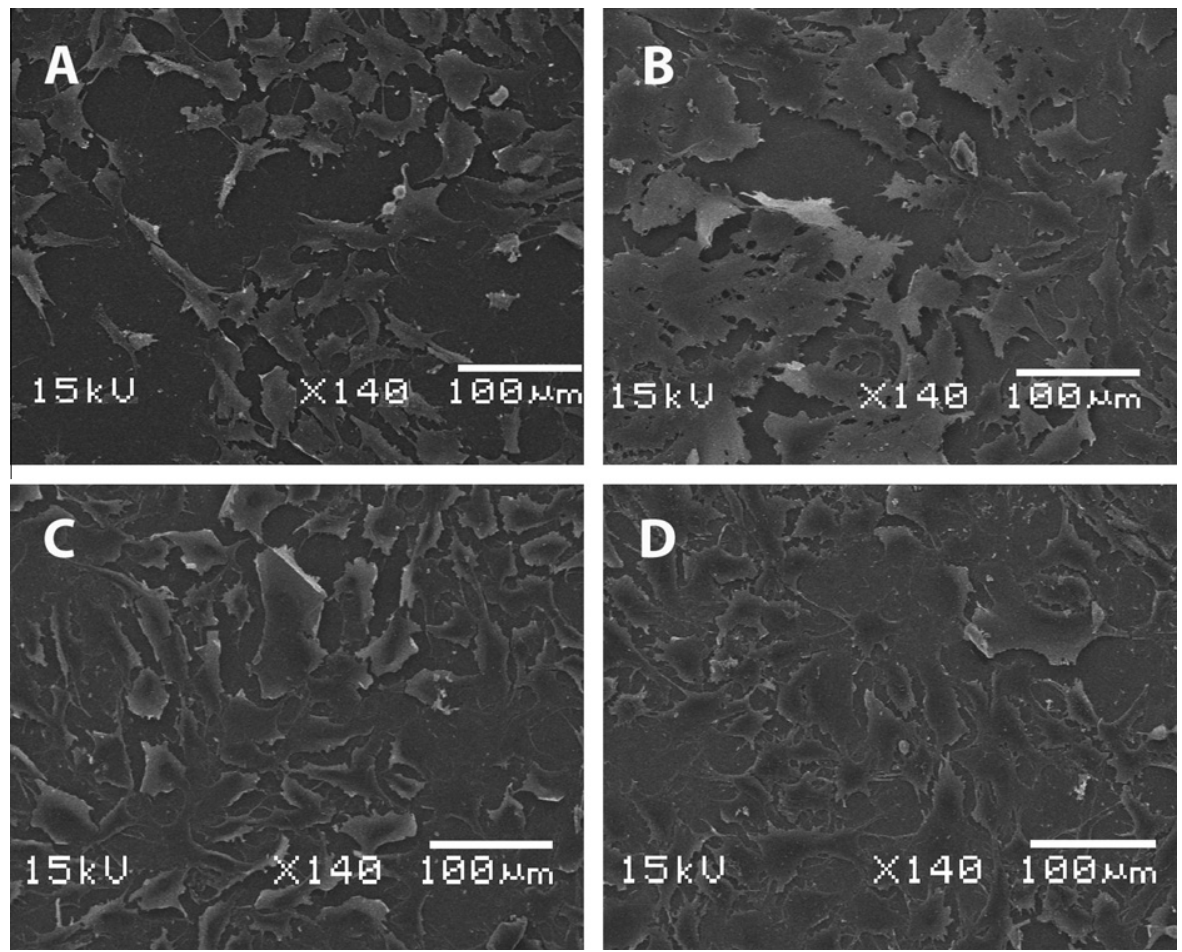

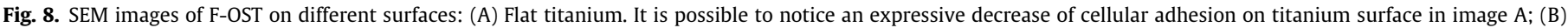
nanostructured titanium without DLC film; (C) DLC/DMF on nanostructured titanium; (D) DLC/ACT on nanostructured titanium.

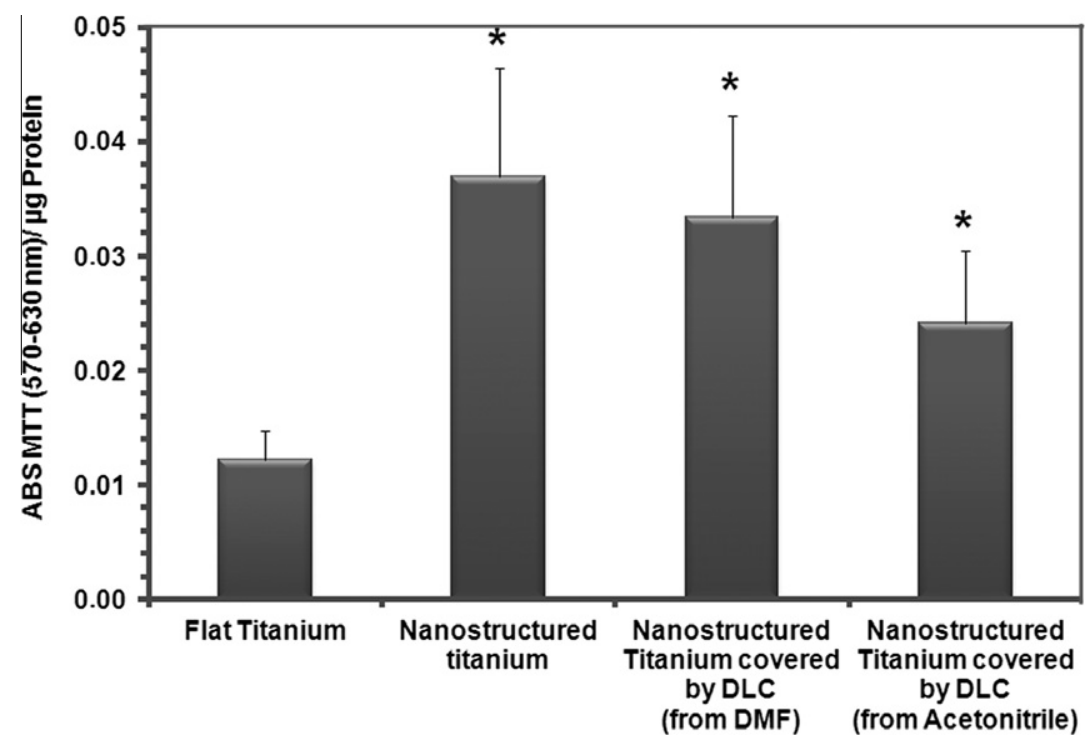

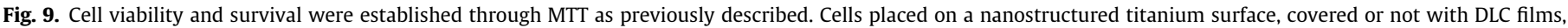

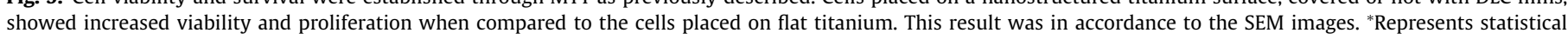

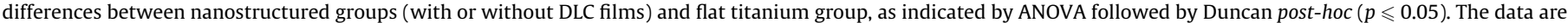
expressed as the mean \pm S.E.M. $(n=4)$.

the nanostructured titanium with or without the DLC films did not affect cell viability when compared to standard cell culture, where cells are seeded on plastic plates (data not shown). Although the nanostructured titanium covered by DLC films statistically did not affect the cellular response when compared to the nanostructured titanium without DLC, the pieces surfaces may be an important factor in maintaining cell viability. In fact, the nanostructurated titanium surface may improve viability by fostering cell adhesion. Taking these cellular response results into account, we found that the DLC films on nanostructured titanium produced by electrodeposition may be a good alternative to improve the quality of prosthesis material that require biocompatibility, good cell adhesion and proliferation, corrosion resistance, high hardness and low friction coefficient.

It is possible to observe a decrease in the cell viability comparing the DLC/DMF and DLC/ACT films that looks like no match with contact angle measurement; however it should be taken in mind that the difference in the MTT test is not significant. In fact, the SEM image (Fig. 8C and D) allows to visualize a good cell adhesion and proliferation on both films. The cell adhesion, spread and 
proliferation depend not only on the surface hydrophilicity, but on its roughness, chemical composition, morphology and texture $[2,5,33]$.

\section{Conclusions}

The titanium nanostructured samples present a hydrophilic character and greater roughness than flat titanium. An increase in cell adhesion, proliferation and cell viability were observed when the titanium surface was nanostructured. Diamond-Like Carbon films electrodeposited on nanostructured samples present no reduction in the biocompatibility compared to nanostructured titanium samples. In addition to the good biocompatibility, the films present superior mechanical properties with low friction coefficient and high hardness. The corrosion resistance of Ti covered with DLC/ACT shows higher values in the high frequency region than the specimens covered with DLC/DMF for all immersion times tested, thus characterizing DLC/ACT as the best anti-corrosion film among the tested ones.

Considering the one of the most useful applications of titanium, the dentistry, and the improvement in corrosion, nanohardness and cell viability conferred by DLC films, DLC coated titanium samples obtained by the electrodeposition technique could be a cheap alternative to obtain DLC coated dental implants, however, further tests like in vivo tests are needed.

\section{Acknowledgments}

The authors are grateful to the Brazilian agencies CAPES, CNPq and FAPEMIG.

\section{References}

[1] S. Tamilselvi, V. Raman, N. Rajendran, Corrosion behaviour of Ti-6Al-7Nb and Ti-6Al-4V ELI alloys in the simulated body fluid solution by Electrochemical Impedance Spectroscopy, Electrochim. Acta 52 (2006) 839-846.

[2] C.A. Elias, Y. Oshida, J.H.C. Lima, C.A. Muller, Relationship between surface properties (roughness, wettability and morphology) of titanium and dental implant removal torque, J. Mech. Behav. Biomed. 1 (2008) 234-242.

[3] K. Das, A. Bandyopadhyay, S. Bose, Biocompatibility and in situ growth of $\mathrm{TiO}_{2}$ nanotubes on Ti using different electrolyte chemistry, J. Am. Ceram. Soc. 91 (2008) 2808-2814

[4] T. Kokubo, H.-M. Kim, M. Kawashita, T. Nakamura, Bioactive metals: preparation and properties, J. Mater. Sci.: Mater. Med. 15 (2004) 99-107.

[5] L. Ponsonnet, K. Reybier, N. Jaffrezic, V. Comte, C. Lagneau, M. Lissac, C. Martelet, Relationship between surface properties (roughness, wettability) of titanium and titanium alloys and cell behaviour, Mater. Sci. Eng. C 23 (2003) $551-560$.

[6] S.K. Kim, J.B. Lee, J.Y. Koak, S.J. Heo, K.R. Lee, L.R. Cho, S.S. Lee, An abutment screw loosening study of a diamond like carbon-coated CP titanium implant, J. Oral Rehabil. 32 (2005) 346-350.

[7] T.M. Manhabosco, S.M. Tamborim, C.B. dos Santos, I.L. Muller, Tribological, electrochemical and tribo-electrochemical characterization of bare and nitrided Ti6Al4V in simulated body fluid solution, Corros. Sci. 53 (2011) 1786-1793.

[8] C.H. Hager, J.H. Sanders, S. Sharma, Characterization of mixed and gross slip fretting wear regimes in Ti6Al4V interfaces at room temperature, Wear 257 (2004) 167-180.

[9] T.M. Manhabosco, I.L. Muller, Tribocorrosion of diamond-like carbon deposited on Ti6Al4V, Tribol. Lett. 33 (2009) 193-197.
[10] C. Meunier, Y. Stauffer, A. Daglar, F. Chai, S. Mikhailov, H.F. Hildebrand, Comparison of hydrogenated and unhydrogenated carbon films obtained by FCVA onto Ti6Al4V: structure, hardness and biocompatibility study, Surf. Coat Technol. 200 (2006) 6346-6349.

[11] R. Hauert, A review of modified DLC coatings for biological applications, Diamond Relat. Mater. 12 (2003) 583-589.

[12] K. Bobzin, N. Bagcivan, S. Theiss, K. Yilmaz, Hydrogen content variation for enhancing the lubricated tribological performance of DLC coatings with ester, Surf. Coat. Technol. 205 (2011) S89-S93.

[13] H.C. Cheng, S.Y. Chiou, C.M. Liu, M.H. Lin, C.C. Chen, K.L. Ou, Effect of plasma energy on enhancing biocompatibility and hemocompatibility of diamond-like carbon film with various titanium concentrations, J. Alloys Comp. 477 (2009) 931-935.

[14] M. Grischke, A. Hieke, F. Morgenweck, H. Dimigen, Variation of the wettability of DLC-coatings by network modification using silicon and oxygen, Diamond Relat. Mater. 7 (1998) 454-458.

[15] T.M. Manhabosco, I.L. Muller, Electrodeposition of diamond-like carbon (DLC) films on Ti, Appl. Surf. Sci. 255 (2009) 4082-4086.

[16] A. Kumar, D. Kennard, Diamond-like carbon coated dental retaining screws, US Patent n' US 6,447,295 B1, September 10, 2002.

[17] C. Casiraghi, F. Piazza, A.C. Ferrari, D. Grambole, J. Robertson, Bonding in hydrogenated diamond-like carbon by Raman spectroscopy, Diamond Relat. Mater. 14 (2005) 1098-1102.

[18] W.C. Oliver, G.M. Pharr, An improved technique for determining hardness and elastic-modulus using load and displacement sensing indentation experiments, J. Mater. Res. 7 (1992) 1564-1583.

[19] M.B. Hansen, S.E. Nielsen, K. Berg, Re-examination and further development of a precise and rapid dye method for measuring cell growth/cell kill, J. Immunol Methods 119 (1989) 203-210.

[20] G.L. Peterson, Review of the Folin phenol protein quantitation method of Lowry, Rosebrough, Farr and Randall, Anal. Biochem. 100 (1979) 201-220.

[21] G. Altankov, F. Grinnell, T. Groth, Studies on the biocompatibility of materials: fibroblast reorganization of substratum-bound fibronectin on surfaces varying in wettability, J. Biomed. Mater. Res. 30 (1996) 385-391.

[22] V. Gribanova, A.N. Zhukov, I.E. Antonyuk, C. Benndorf, E.N. Baskova, Effect of the acidity ppof aqueous solutions on the wettability of diamond, graphite and pyrocarbon surfaces, Diamond Relat. Mater. 9 (2000) 1-6.

[23] L.Yu. Ostrovskaya, Studies of diamond and diamond-like film surfaces using XAES, AFM and wetting, Vacuum 68 (2003) 219-238.

[24] R. Paul, S. Dalui, S.N. Das, R. Bhar, A.K. Pal, Hydrophobicity in DLC films prepared by electrodeposition technique, Appl. Surf. Sci. 255 (2008) 17051711.

[25] H.Y. Hu, G. Chen, J.Y. Zha, Facile synthesis of CNTs-doped diamond-like carbon film by electrodeposition, Surf. Coat. Technol. 202 (2008) 5943-5946.

[26] X.B. Yan, T. Xu, G. Chen, H.W. Liu, S.R. Yang, Effect of deposition voltage on the microstructure of electrochemically deposited hydrogenated amorphous carbon films, Carbon 42 (2004) 3103-3108.

[27] R.S. Lillard, D.P. Butt, T.N. Taylor, K.C. Walter, M. Nastasi, The breakdown mechanism of diamond-like carbon coated nickel in chloride solution, Corros. Sci. 39 (1997) 1605-1624.

[28] A.F. Galio, L. Shaeffer, I.L. Muller, Corrosion behavior and biocompatibility of titanium screws produced by powder injection moulding (PIM) for temporary applications, Recent Patents on Mechanical Engineering 4 (2011) 47-54.

[29] J. Pan, D. Thierry, C. Leygraf, Electrochemical Impedance Spectroscopy study of the passive oxide film on titanium for implant application, Electrochim. Acta 41 (1996) 1143-1153.

[30] Y. Yan, A. Neville, D. Dowson, Biotribocorrosion of CoCrMo orthopaedic implant materials - assessing the formation and effect of the biofilm, Tribol. Int. 40 (2007) 1492-1499.

[31] S. Kumar, T.S.N.S. Narayanan, S.G.S. Raman, S.K. Seshadri, Fretting corrosion behaviour of thermally oxidized CP-Ti in Ringer's solution, Corros. Sci. 52 (2010) 711-721.

[32] H. Amel-Farzad, M.T. Peivandi, S.M.R. Yusof-Sani, In-body corrosion fatigue failure of a stainless steel orthopaedic implant with a rare collection of different damage mechanisms, Eng. Fail. Anal. 14 (2007) 1205-1217.

[33] A. Méndez-Vilas, M.G. Donoso, J.L. González-Carrasco, M.L. González-Martín, Looking at the micro-topography of polished and blasted Ti-based biomaterials using atomic force microscopy and contact angle goniometry, Colloids Surf. B 52 (2) (2006) 157-166. 